\title{
O050. Chronic daily headache and body mass index: a meta-analysis of observational studies
}

\author{
Cindy Tiseo*, Diana Degan, Raffaele Ornello, Amleto Gabriele, Francesca Pistoia, Antonio Carolei, Simona Sacco
}

From Abstracts from the 1st Joint ANIRCEF-SISC Congress

Rome, Italy. 29-31 October 2015

\section{Background}

Many studies have investigated the association between chronic daily headache $(\mathrm{CDH})$ and normal weight, preobesity, and obesity, with controversial results. A metaanalysis of observational studies was conducted in order to clarify the association between $\mathrm{CDH}$ and body mass index (BMI) categories.

\section{Methods}

Studies published up to April 2015 about the association between $\mathrm{CDH}$ and BMI were systematically searched from multiple electronic databases. We included in the analysis observational studies in the English language with $\mathrm{CDH}$ as outcome variables, and pre-obesity or obesity as compared with normal weight as exposure variables. Only the studies which defined BMI categories according to the World Health Organization criteria for the Western population were included (underweight, $<18.5 \mathrm{Kg} / \mathrm{m}^{2}$; normal range, $18.5-24.9 \mathrm{Kg} / \mathrm{m}^{2}$; overweight, $\geq 25.0 \mathrm{Kg} / \mathrm{m}^{2}$; pre-obesity, $25.0-29.9 \mathrm{Kg} / \mathrm{m}^{2}$; class I obesity $30.0-34.9 \mathrm{Kg} / \mathrm{m}^{2}$; class II obesity $35.0-39.9 \mathrm{Kg} / \mathrm{m}^{2}$; class III obesity $\geq 40.0 \mathrm{Kg} / \mathrm{m}^{2}$ ). Pooled adjusted effect estimate (PAEE) with $95 \%$ confidence interval $(\mathrm{CI})$ was calculated to examine the strength of the association using random-effects models.

\section{Results}

Out of 2,022 records, 4 studies [1-4] met the selection criteria and were included in the meta-analysis. The pooled analysis suggested an increased risk of having $\mathrm{CDH}$ in obese subjects (PAEE 1.48; 95\% CI, 1.10; 1.98; $\mathrm{p}=0.009$ ) as compared to normal weight subjects, while the risk in pre-obese subjects was not different when compared to that of normal weight subjects (PAEE 1.13; 95\% CI 0.931.39; $\mathrm{p}=0.223$ ) (Figure 1). Data analysis according to BMI categories found that subjects with grade II-III obesity had

\footnotetext{
* Correspondence: cindy.tiseo@gmail.com
}

Department of Neurology, University of L'Aquila, L'Aquila, Italy a higher risk of CDH (PAEE 1.94; 95\% CI, 1.50-2.51; $\mathrm{p}<0.001)$ than normal weight subjects, while grade I obesity was not associated with a higher risk of CDH (PAEE 1.05; 95\% CI 0.43-2.59; $\mathrm{p}=0.909$ ) (Figure 2).

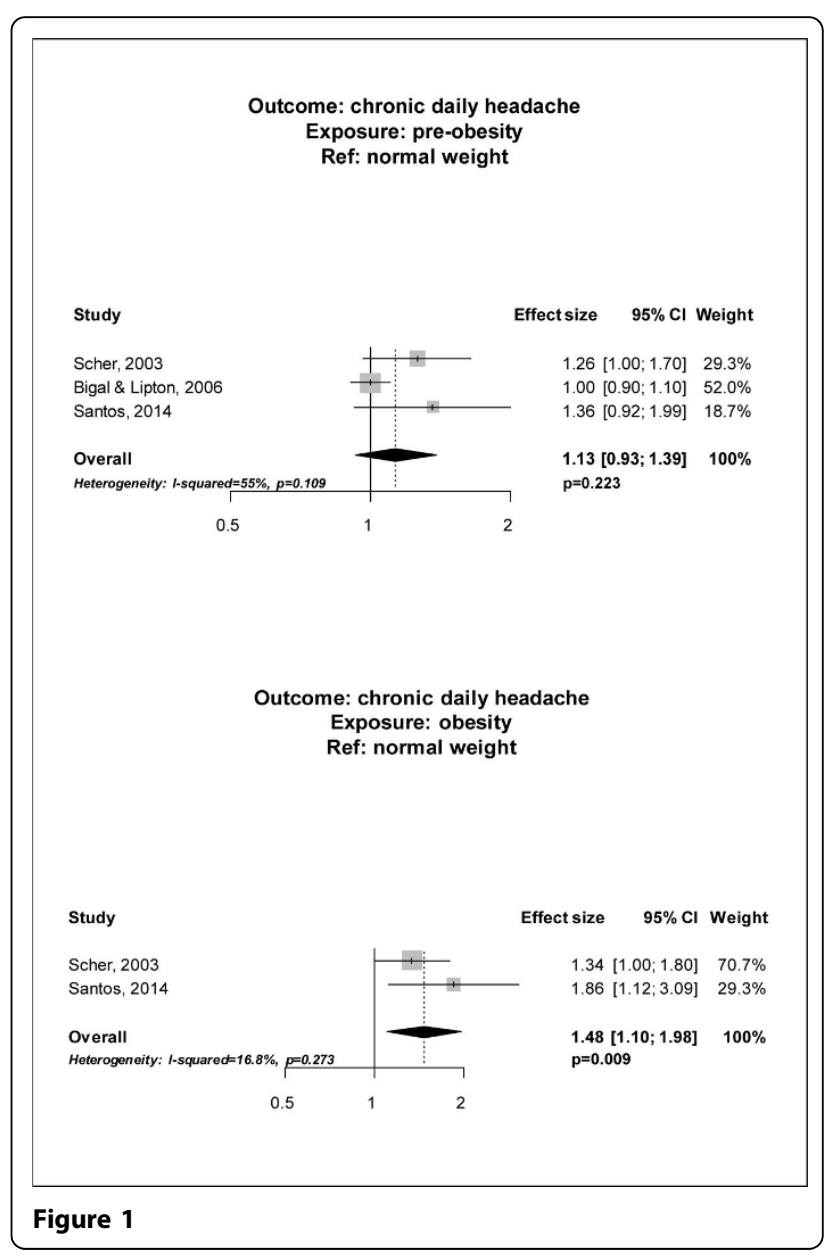

\section{SpringerOpen ${ }^{\circ}$}

(C) 2015 Tiseo et al. This is an Open Access article distributed under the terms of the Creative Commons Attribution License (http:// creativecommons.org/licenses/by/4.0), which permits unrestricted use, distribution, and reproduction in any medium, provided the original work is properly cited. The Creative Commons Public Domain Dedication waiver (http://creativecommons.org/publicdomain/ zero/1.0/) applies to the data made available in this article, unless otherwise stated. 


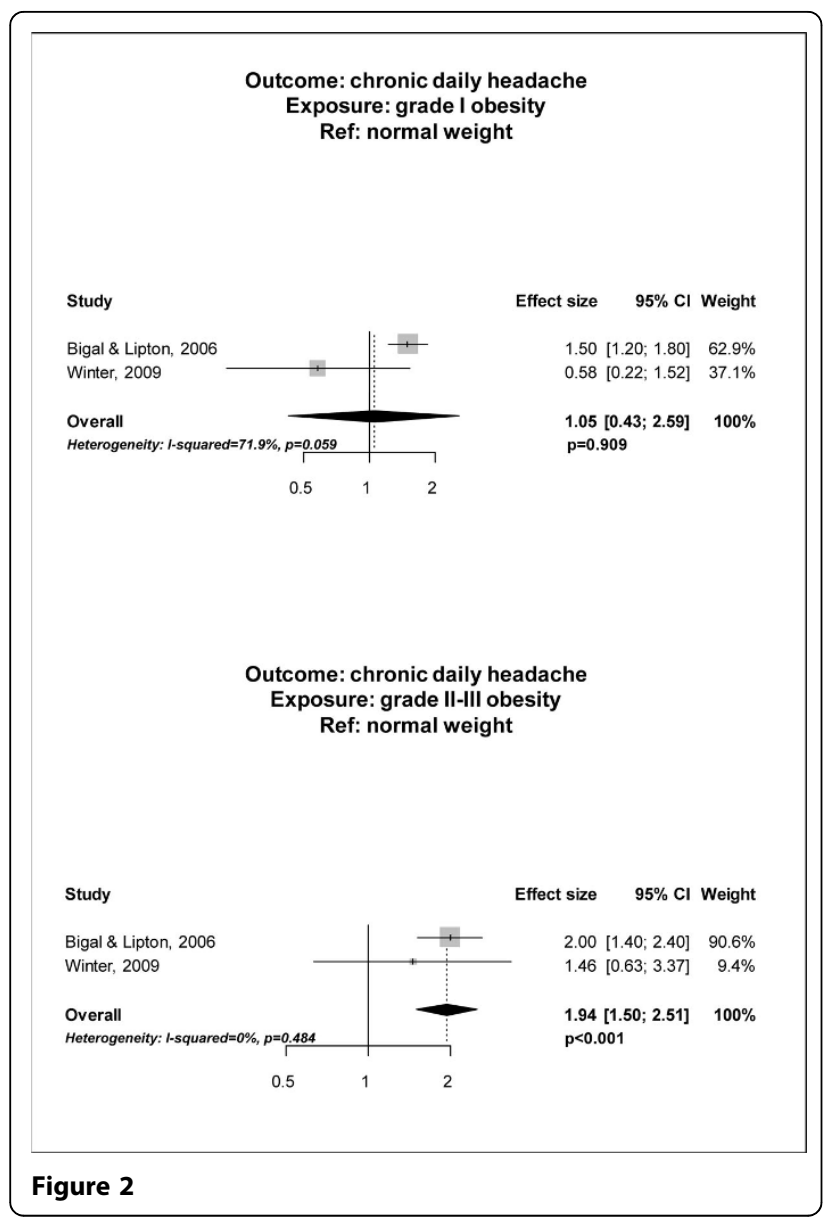

\section{Conclusions}

According to this meta-analysis of observational studies there is an association between $\mathrm{CDH}$ and moderate and severe obesity. This association suggests that body weight management may be a viable strategy for the prevention of chronification in patients suffering from both migraine and tension-type headache.

Published: 28 September 2015

\section{References}

1. Scher Al, Stewart WF, Ricci JA, Lipton RB: Factors associated with the onset and remission of chronic daily headache in a population-based study. Pain 2003, 106(1-2):81-89.

2. Bigal ME, Lipton RB: Obesity is a risk factor for transformed migraine but not chronic tension-type headache. Neurology 2006, 67(2):252-257.

3. Winter AC, Berger $K$, Buring JE, Kurth T: Body mass index, migraine, migraine frequency and migraine features in women. Cephalalgia 2009, 29(2):269-278

4. Santos IS, Goulart AC, Passos VM, Del Carmen Molina M, Lotufo PA, Bensenor IM: Obesity, abdominal obesity and migraine: A cross-sectional analysis of ELSA-Brasil baseline data. Cephalalgia 2015, 35(5):426-36, Epub 2014 Aug 12.
doi:10.1186/1129-2377-16-S1-A64

Cite this article as: Tiseo et al:: O050. Chronic daily headache and body mass index: a meta-analysis of observational studies. The Journal of Headache and Pain 2015 16(Suppl 1):A64.

\section{Submit your manuscript to a SpringerOpen ${ }^{\circ}$ journal and benefit from:}

- Convenient online submission

- Rigorous peer review

- Immediate publication on acceptance

- Open access: articles freely available online

- High visibility within the field

- Retaining the copyright to your article

Submit your next manuscript at $>$ springeropen.com 